\title{
Hepatitis grave producida por intoxicación con té verde en un niño. Presentación de un caso
}

\author{
Severe hepatitis caused by green tea intoxication in a child. Case report
}

\author{
Dr. Daniel D'Agostino ${ }^{a}$ Dra. María L. Cavalieria y Dra. María S. Arcuccia
}

\begin{abstract}
RESUMEN
El daño hepático inducido por hierbas es una reacción adversa relacionada con el uso de medicina herbaria, incluida en el grupo de daño hepático inducido por drogas. El uso terapéutico de hierbas medicinales es cada vez más frecuente por la creencia de que los productos naturales o hierbas son siempre seguros. En Estados Unidos, la incidencia de toxicidad alcanza un $9 \%$ y, en países de Asia, un 19-63\% de los casos totales de daño hepático inducido por drogas.

El té verde es obtenido de las hojas de la Camellia sinensis. Las hojas recién cosechadas son estabilizadas por calentamiento en seco para inactivar la enzima polifenol y luego se secan rápidamente. Su consumo ha aumentado en los últimos años, y se han documentado reacciones hepatotóxicas.

Se presenta un caso de hepatitis aguda grave asociada al consumo de té verde en un niño de 2 años.

Palabras clave: té verde, Camellia sinensis, enfermedad hepática inducida por sustancias y drogas, hepatitis tóxica, niños.
\end{abstract}

\begin{abstract}
Herb-induced liver injury is a type of adverse drug reaction related to using herbal medicine, and now is a segment of druginduced liver injury. The use of herbal products has increased significantly, because it is generally regarded as safe and natural by the public. In the United States, the incidence reaches $9 \%$ and, in the countries of Asia, 19-63\% of the total cases of druginduced liver injury. Green tea is obtained from the leaves of the Camellia sinensis. Freshly harvested leaves are stabilized by dry heating to inactivate the polyphenol enzyme and then dried quickly. Its consumption has increased in recent years and has been reported with hepatotoxic reactions.

We present a case of severe hepatitis related to the consumption of green tea in a 2-year-old child.

Key words: green tea, Camellia sinensis, chemical and drug induced liver injury, toxic hepatitis, children.
\end{abstract}

http: / / dx.doi.org/10.5546/ aap.2019.e655

Cómo citar: D’Agostino D, Cavalieri ML, Arcucci MS. Hepatitis grave producida por intoxicación con té verde en un niño. Presentación de un caso Arch Argent Pediatr 2019;117(6):e655-e658.

a. Servicio de Gastroenterología, Hepatología y Trasplante Hepático e Intestinal Pediátrico del Hospital Italiano de Buenos Aires, Argentina.

Correspondencia:

Dr.DanielD'Agostino:daniel.dagostino@hospitalitaliano.org.ar

Financiamiento: Ninguno.

Conflicto de intereses: Ninguno que declarar.

Recibido: $19-12-2018$

Aceptado: 26-6-2019

\section{INTRODUCCIÓN}

La hepatotoxicidad inducida por drogas y sustancias es internacionalmente conocida con la sigla en inglés de DILI (drug-induced injury). Los productos herbarios han sido clasificados como suplementos dietéticos, y su consumo se ha incrementado en los últimos años. En 2007, el 17,9\% de los adultos, en Estados Unidos, reportó la utilización de un suplemento herbario en el año previo. Desde 1994, los suplementos dietéticos no requieren evaluación ni aprobación por parte de la Food and Drug Administration (FDA). ${ }^{1}$

Numerosos productos herbarios que se comercializan bajo la etiqueta de favorecedores de la pérdida de peso y del bienestar general contienen extracto de té verde (ETV). Este ingrediente es, según la publicidad, el responsable de incrementar el metabolismo y quemar grasa. Aunque el ETV ha mostrado tener propiedades termogénicas, también ha sido implicado en lesiones hepáticas, tanto en estudios in vitro como in vivo. Varios informes clínicos proporcionan evidencia convincente del potencial tóxico del té verde (TV) en los humanos. ${ }^{2}$

Se comunican, según nuestro entender y por primera vez en nuestro medio, las características clínicas y el análisis de laboratorio de un niño pequeño con hepatotoxicidad asociada con el suministro crónico de TV.

\section{CASO CLÍNICO}

Se trataba de un varón de 29 meses de edad que consultó al Servicio de Hepatología de nuestro Hospital por hepatitis aguda grave de dos semanas de evolución.

Como antecedentes personales, era un recién nacido de término, 37 semanas, con peso al nacer de $3100 \mathrm{~g}$, embarazo gemelar. A los 6 meses de vida, se le diagnosticó alergia a la proteína de la leche de vaca, por lo cual realizó una dieta de exclusión de lácteos hasta el año de edad. A partir de ese momento, presentó aversión a la leche y fue reemplazada, por su madre, por infusiones de TV. Su hermano no recibía TV.

El niño era hijo de padres con estudios universitarios, habitantes de la Ciudad de 
Buenos Aires, que vivían en una casa con servicios completos y negaban viajes recientes. Los antecedentes familiares: madre con lupus eritematoso sistémico, hermano con antecedente de reflujo gastroesofágico y broncoespasmos repetidos.

Como antecedente de la enfermedad actual, un mes antes de la internación, el niño había presentado otitis media aguda tratada con amoxicilina a razón de $90 \mathrm{mg} / \mathrm{kg} /$ día durante 7 días, exantema y diarrea aguda mucosa durante 5 días, con rescate de rotavirus en la materia fecal. Por la persistencia de la fiebre, a los 10 días, se realizó, en otro centro asistencial, un análisis de laboratorio que evidenció como único dato positivo alanino aminotransferasa (ALT) de $400 \mathrm{mg} / \mathrm{dl}$. Con este resultado, concurrió en forma ambulatoria al Servicio de Hepatología de nuestro Centro.

Al momento del examen físico, el niño se encontraba en buen estado general, anictérico, con el hígado palpable a $2 \mathrm{~cm}$ del reborde costal, sin esplenomegalia, con un peso de $15 \mathrm{~kg}$ (percentilo 90), una talla de $80 \mathrm{~cm}$ (percentilo 25), con índice de masa corporal de $20 \mathrm{~kg} / \mathrm{m}^{2}$ (percentilo > 97) y no refería coluria ni acolia. El análisis de laboratorio mostró serologías virales y autoanticuerpos negativos (los controles periódicos de laboratorio se observan en la Tabla 1).

Al momento del interrogatorio, la madre refirió que el TV era la única bebida que el niño aceptaba tomar y que se lo había suministrando desde 5 meses antes, a razón de 2 a 3 tazas por día, durante el desayuno y la merienda (saquito de té de $0,8 \mathrm{~g}$ de TV; cada taza de TV aportaba
80-106 mg de polifenoles, que sería equivalente a $36-47,7 \mathrm{~g}$ en 5 meses).

Pensando en el TV como agente hepatotóxico, se le indicó a la familia suspender dicha infusión y continuar el control evolutivo. A las 24 horas de haberse suspendido el TV, un nuevo estudio informó aspartato aminotransferasa (AST) de 2536, ALT de 1679, con tiempo de protrombina del $70 \%$, razón internacional normalizada (international normalized ratio; INR, por sus siglas en inglés) de 1,2, y factor $\mathrm{V}$ del $85 \%$. Con dichos resultados, se decidió su internación para su control clínico y la ampliación de los estudios.

Se realizó un análisis de laboratorio diario con hepatograma (Figura 1); el proteinograma, dosaje de alfa-1-antitripsina y la función renal fueron normales. La ecografía abdominal con doppler color informó hígado con un discreto aumento de tamaño y signos de edema periportal, vesícula de paredes finas, sin evidencia de imágenes litiásicas, vía biliar intra- y extrahepática no dilatadas, flujos hepáticos y extrahepáticos permeables. Las serologías fueron normales: anticuerpos contra hepatitis A y anticuerpos contra el antígeno de superficie (hepatitis B surface antigen antibody; $H B s A b$, por sus siglas en inglés) positivos, antígenos de superficie de hepatitis $B$ negativo, citomegalovirus, virus de EpsteinBarr, monotest, virus de hepatitis $\mathrm{C}$, parvovirus y Mycoplasma (todos negativos).

Los estudios para descartar una causa autoinmune, C3, C4 y niveles en sangre de inmunoglobulinas, estuvieron dentro de los límites normales, anticuerpos antinucleares, anticuerpos microsomales de hígado (anti liver

TABLA 1. Seguimiento de los análisis de laboratorio

\begin{tabular}{|c|c|c|c|c|c|c|c|}
\hline & 1.er control & A las $48 \mathrm{~h}$ & $\begin{array}{c}\text { Se suspende } \\
\text { el TV }\end{array}$ & $\begin{array}{c}48 \mathrm{~h} \\
\sin \mathrm{TV}\end{array}$ & $\begin{array}{c}\text { A los } 15 \text { días } \\
\text { del inicio }\end{array}$ & $\begin{array}{c}\text { Al mes } \\
\text { del inicio }\end{array}$ & $\begin{array}{c}\text { Alta a los } \\
2 \text { meses }\end{array}$ \\
\hline $\mathrm{BT}(\mathrm{mg} / \mathrm{dl})$ & 2,52 & 3,62 & 1,55 & 1,31 & 1,1 & 0,63 & 0,21 \\
\hline $\mathrm{BD}(\mathrm{mg} / \mathrm{dl})$ & 1,6 & 2,27 & 0,66 & 0,63 & 0,49 & 0,22 & 0,09 \\
\hline FAL (UI/I) & 482 & 426 & 374 & 353 & 360 & 296 & 204 \\
\hline AST (UI/I) & 1453 & 1918 & 2154 & 1947 & 1542 & 213 & 26 \\
\hline $\operatorname{ALT}(\mathrm{UI} / \mathrm{I})$ & 1500 & 1530 & 1471 & 1434 & 1363 & 344 & 26 \\
\hline GGT (UI/I) & 186 & 160 & 141 & 135 & 134 & 65 & 10 \\
\hline $\mathrm{TP}(\%)$ & 112 & 107 & 102 & 102 & 100 & 86 & 96 \\
\hline $\operatorname{ALB}(\mathrm{g} / \mathrm{dl})$ & 3,81 & 4,02 & 3,99 & 3,98 & 3,9 & 4,25 & 3,7 \\
\hline RIN & & 0,96 & & & & 1,1 & 1,03 \\
\hline Amonio (ng/dl) & & & 88 & 122 & & 59 & \\
\hline
\end{tabular}

BT: bilirrubina total; BD: bilirrubina directa; FAL: fosfatasa alcalina; AST: aspartato aminotransferasa; ALT: alalino aminotransferasa; GGT: gamma-glutamil transpeptidasa; TP: tiempo de protrombina; ALB: albúmina; RIN: razón internacional normalizada; TV: té verde. 
kidney microsome; anti LKM, por sus siglas en inglés), anti músculo liso negativos (actina negativo), perfil hepático autoinmune ampliado (SLA, LC 1, Gp-210, AMA-M 2 LKM 1, Sp 100) y anticuerpos para celiaquía negativos. Fue evaluado por el Servicio de Toxicología, quienes interrogaron sobre hongos, solventes, otros medicamentos, y no surgieron otros hepatotóxicos. El paciente presentó una elevación de las enzimas hepáticas AST y ALT con un valor máximo de 2500 y 1600, respectivamente.

Cuatro días después de la suspensión del $\mathrm{TV}$, comenzó un descenso significativo y se decidió posponer la realización de la biopsia hepática. Habiendo descartado causas infecciosas, autoinmunes, metabólicas, otros hepatotóxicos, con la mejoría sostenida de su análisis de laboratorio y continuando en buen estado físico, se otorgó el egreso hospitalario con el diagnóstico de hepatitis grave asociada al consumo crónico de TV. Continuó con el control ambulatorio irregular; los padres no asistieron a todas las consultas indicadas, pero sí realizaron los controles de laboratorio. A los tres meses del alta, el análisis de laboratorio mostró un hepatograma normal.

\section{DISCUSIÓN}

Las lesiones provocadas por drogas, hierbas, suplementos dietéticos y productos para mejorar el rendimiento físico son, actualmente, un serio problema que afecta a la población general y alcanza a niños y a adolescente en todas sus edades. La intoxicación por estos productos puede ocasionar un 10-20\% de hepatitis aguda grave y requerir trasplante de hígado.,4

Las hojas del TV y del té negro provienen de Camellia sinensis; la diferencia entre ambos es que el segundo se oxida y el primero puede ser fermentado. ${ }^{5} \mathrm{El} \mathrm{TV}$ contiene varios flavonoides polifenólicos y catequinas; el más abundante de ellos es la epigalocatequina galato (epiogallocatechin gallate; EGCG, por sus siglas en inglés). Se ha afirmado que esta posee propiedades antiobesidad a través de su actividad de inhibición de las enzimas lipogénicas. ${ }^{6}$

El análisis farmacocinético del TV y sus diferentes catequinas, particularmente la EGCG, ha sido explorada en los humanos. La dosis estimada de EGCG en los humanos que podría producir toxicidad es de 30-90 mg/ kg por día, lo que equivale a 10-32 tazas de TV. Esto está muy

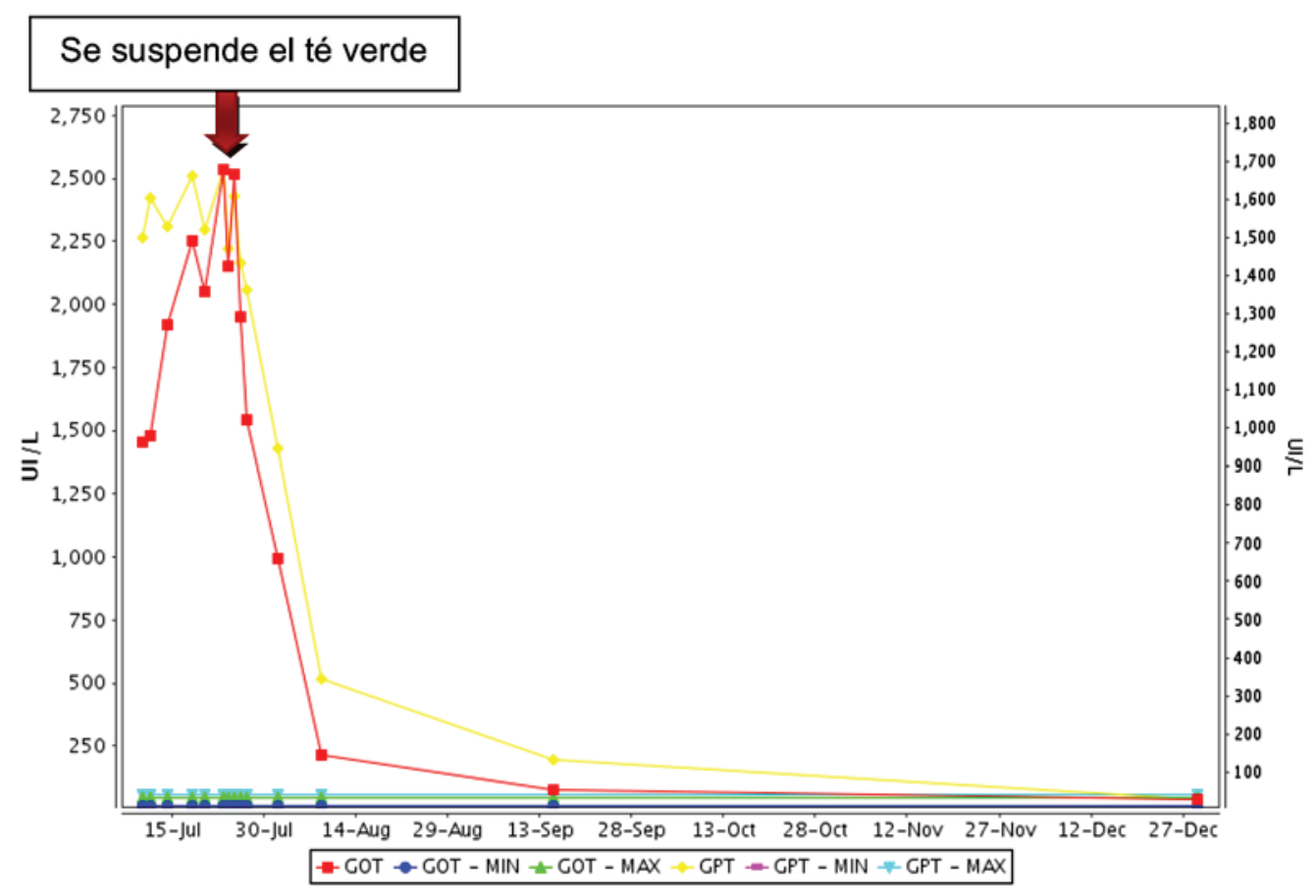

GOT: transaminasa glutámico-oxalacética; GPT: transaminasa glutámico-pirúvica. 
por encima de la usual dosis recomendada de TV en los suplementos para bajar de peso, lo cual indicaría que la lesión hepática por TV podría ser una reacción idiosincrática. ${ }^{7,8}$

Además, está descrito que la lesión hepática causada por altas dosis de TV parece ser el resultado del estrés oxidativo y apoptosis hepatocelular. Tal lesión se refleja histológicamente en un patrón de necrosis hepatocelular. ${ }^{9-11}$

En el caso presentado, habiéndose descartado causas infecciosas, autoinmunes, metabólicas y otros hepatotóxicos, y de acuerdo con la pronta recuperación que se obtuvo luego de la suspensión del TV, aun teniendo en cuenta los antecedentes de otitis tratada con amoxicilina y el episodio de diarrea por rotavirus, el diagnóstico presuntivo final fue hepatitis aguda grave secundaria a toxicidad por TV. Al ser el primer caso documentado en la Argentina, se quiere alertar sobre esta intoxicación y realizar acciones dirigidas a la prevención y al control de su administración en los niños.

El uso de hierbas medicinales es cada vez más frecuente, basado, fundamentalmente, en la creencia de que los productos naturales o hierbas son siempre seguros. Este caso podría colaborar para la difusión de los riesgos relacionados con el consumo de sustancias herbáceas que pueden recibir los niños y los adolescentes.

\section{REFERENCIAS}

1. Stickel F, Patsenker E, Schuppan D. Herbal hepatotoxicity. J Hepatol. 2005; 43(5):901-10.

2. Patel S, Beer S, Kearney D, Phillips G, et al. Green tea extract: A potential cause of acute liver failure. World J Gastroenterol. 2013; 19(31):5174-7.

3. Amin M, Harpavat S, Leung D. Drug-induce liver injury in children. Curr Opin Pediatr. 2015; 27(5):625-33.

4. Molleston J, Fontana R, Lopez M, Kleiner D, et al. Characteristics of Idiosyncratic Drug-induced Liver Injury in Children: Results From the DILIN Prospective Study. J Pediatr Gastroenterol Nutr. 2011; 53(2):182-9.

5. Arzenton E, Magro L, Paon V, Capra F, et al. Acute hepatitis caused by green tea infusion: a case report. Adv Pharmacoepidemiol Drug Saf. 2014; 3(4):170.

6. MazzantiG, DiSotto A, Vitalone A. Hepatotoxicity of green tea: an update. Arch Toxicol. 2015; 89(8):1175-91.

7. Wang J, Zhu Y, Bai Z, Wang F, et al. Guidelines for the Diagnosis and Management of Herb-Induced Liver Injury. Chin J Integr Med. 2018; 24(9):696-706.

8. Navarro V, Khan I, Björnsson E, Seeff L, et al. Liver Injury from Herbal and Dietary Supplements. Hepatology. 2017; 65(1):363-73.

9. García-Cortés M, Borraz Y, Lucena MI, Peláez G, et al. Hepatotoxicidad secundaria a "productos naturales": análisis de los casos notificados al Registro Español de Hepatotoxicidad. Rev Esp Enferm Dig. 2008; 100(11):688-95.

10. Cavalieri ML, D' Agostino D. El hígado y la toxicidad por drogas, hierbas y suplementos dietéticos. Arch Argent Pediatr. 2017; 115(6):e397-403.

11. National Institutes of Health. LiverTox Database: Clinical and Research Information on Drug-Induced Liver Injury. [Acceso: julio de 2018]. Disponible en: https:/ / livertox. nlm.nih.gov. 